\title{
Hemophagocytic Lymphohistiocytosis in Adults with Intraocular Involvement: Clinicopathologic Features of 3 Cases
}

\author{
M. Adelita Vizcaino ${ }^{a, c}$ Charles G. Eberhartt ${ }^{a}$ b Fausto J. Rodriguez ${ }^{a, b}$ \\ ${ }^{a}$ Division of Neuropathology and b Sydney Kimmel Comprehensive Cancer Center, Johns Hopkins University \\ School of Medicine, Baltimore, MD, USA; ' Department of Cellular and Tissue Biology, Faculty of Medicine, UNAM, \\ Mexico City, Mexico
}

\section{Keywords}

Hemophagocytic lymphohistiocytosis · Hemophagocytic syndrome - Multisystemic inflammation · Adult-onset hemophagocytosis · Uvea · Retina tologic features in the eye are poorly documented, with prior reports restricted to children. Our 3 adult cases are reported using updated criteria and, despite the difference in age, show changes similar to those observed in the pediatric population.

๑) 2017 S. Karger AG, Basel

\begin{abstract}
Background/Aims: Hemophagocytic lymphohistiocytosis $(\mathrm{HLH})$ is an infrequent inflammatory multisystemic syndrome. Only rare cases with ophthalmic involvement describing their pathologic features have been previously reported. Methods: We report 3 cases of adult-onset HLH with bilateral ocular involvement and describe their clinicopathologic features. Results: Three adult males -2 with a history of viral infection - developed persistent fever, fatigue, bone marrow abnormalities, and irreversible multiorgan failure. Visual impairment was also documented in 2 cases. Complete autopsies were performed. Ophthalmic pathology demonstrated a bilateral histiocytic infiltrate with scant lymphocytes affecting the uvea. Focal extension to the retina, optic nerve, and trabecular meshwork were also identified, as well as hemophagocytosis in 1 case. Macrophages showed strong immunoreactivity for CD163 antibody and lacked BRAF p.V600E mutant protein. Conclusion: HLH is an unusual disorder associated with several systemic conditions. His-
\end{abstract}

\section{KARGER}

(C) 2017 S. Karger AG, Basel

E-Mail karger@karger.com

www.karger.com/oop

\section{Introduction}

Hemophagocytic lymphohistiocytosis (HLH), also known as hemophagocytic syndrome, is a rare, heterogeneous group of disorders resulting from multisystemic inflammation caused by hyperactivated macrophages and lymphocytes that produce large amounts of cytokines [13]. Unless treated aggressively, it is rapidly lethal. It usually presents in children $<1$ year of age, particularly in patients $<6$ months $[1,4,5]$. Nevertheless, late onset in adolescents and adults is well-documented, as well as a slight male predominance $[6,7]$. Based on its etiology, HLH is classified as primary (genetic), mainly inherited in either an autosomal recessive or $\mathrm{X}$-linked recessive pattern, or secondary (reactive or acquired) (Table 1) [8,9]. As the name reflects, HLH is histologically characterized by abundant inflammatory cells, mostly histiocytes and vari-

Fausto J. Rodriguez

Johns Hopkins University School of Medicine

Sheikh Zayed Tower, Room M2101, 1800 Orleans Street

Baltimore, MD 21231 (USA)

E-Mail frodrig4@jhmi.edu 
able numbers of lymphocytes, infiltrating a variety of tissues. Even though hemophagocytosis is a distinctive finding typically seen in bone marrow, spleen, and lymph nodes, it may be absent in initial stages of the disease or in other organs. Herein, we report 3 patients who developed adult-onset HLH with bilateral ocular involvement and describe their clinical and histopathologic features.

\section{Materials and Methods}

Clinical information was obtained from retrospective review of the medical records, while systemic and ophthalmic postmortem findings were obtained from the final autopsy reports. The study was performed under approval of the Johns Hopkins Institutional Review Board (NA_00011133 approved 9/14/2013). All hematoxylin and eosin (H\&E) stained slides from the globes and optic nerves were reviewed. Immunostaining for CD163 (clone 10D6, Novocastra, 1:500), CD3 (PS1, Leica, prediluted), CD20 (L26, Dako, 1:200), and BRAF p.V600E (VE1, Ventana, prediluted) was performed. The immunohistochemical protocol included deparaffinization, hydration, antigen retrieval, primary antibody incubation, and detection and visualization according to the manufacturer's instructions.

\section{Results}

\section{Case 1}

\section{Clinical History}

The patient was a 70-year-old male with acquired immunodeficiency syndrome and a past medical history of disseminated varicella-zoster infection, purpuric vasculitis, and central nervous system toxoplasmosis, who presented 2 months prior to his death with severe left-sided headache. The diagnosis of sinusitis was made, and he was treated with ethmoid and sphenoid sinus drainage without improvement. Subsequently, he presented with left visual loss presumably due to central retinal artery occlusion, for which treatment with prednisone was started. Afterwards, he declined progressively with aphasia, hemiparesis, fever, anemia (hemoglobin $9.9 \mathrm{~g} / \mathrm{dL}$ ), and severe leukopenia $\left(1,000 / \mathrm{mm}^{3}\right)$ and died.

\section{Autopsy Findings}

Systemic examination revealed invasive brain aspergillosis affecting the left temporal and parietal lobes, midbrain and pons, as well as old, cystic necrosis consistent with prior, inactive toxoplasmosis. Focal bronchiolar and alveolar hemorrhages were noted in both lungs. Splenomegaly was also present, and hemophagocytosis was found in the spleen, bone marrow, and lymph nodes.
Ophthalmic Pathology

Both globes were grossly unremarkable. Routine H\&E stained slides demonstrated a scant, bilateral inflammatory infiltrate confined to the choroid and trabecular meshwork, consisting mostly of macrophages with only rare lymphocytes. No fungal microorganisms, infarcts, or other findings secondary to central retinal artery occlusion were present. Hemophagocytosis was not identified (Fig. 1), and special stains were negative for microorganisms (GMS, PAS, AFB) or iron (Prussian blue) deposition. CD163 immunohistochemical analysis highlighted numerous histiocytes in the choroid and trabecular meshwork, and more rarely in the retina, optic nerve, ciliary body, and iris. There were no significant CD3-positive T cells or CD20-positive B cells, and immunohistochemical staining for BRAFp.V600E mutant protein was negative.

\section{Case 2}

\section{Clinical History}

The patient was a 20 -year-old male presenting with fever, fatigue, and weight loss 3 months prior to his death. The diagnosis of EBV (+) infectious mononucleosis was made, with persistence of symptoms and aggregate pancytopenia (hemoglobin $6.1 \mathrm{~g} / \mathrm{dL}$, white cells $190 / \mathrm{mm}^{3}$, platelets $78,000 / \mathrm{mm}^{3}$ ), as well as hyperferritinemia $(349,976 \mathrm{ng} / \mathrm{mL})$, hypertriglyceridemia $(484 \mathrm{mg} / \mathrm{dL})$, and hypofibrinogenemia ( $47 \mathrm{mg} / \mathrm{dL}$ ). The bone marrow biopsy showed increased cellularity, left-shifted myelopoiesis, interstitial lymphocytosis, and hemophagocytosis. The diagnosis of HLH was made, and he started treatment with methylprednisolone. However, he developed elevation of serum transaminases, metabolic acidosis, septic shock, and disseminated intravascular coagulation (DIC) and died.

\section{Autopsy Findings}

Postmortem evaluation showed oral candidiasis and multiple hemorrhages in the subarachnoid space, lungs, inferior vena cava, bladder, and ureters, consistent with DIC, as well as hepatosplenomegaly and hemophagocytosis in the bone marrow, liver, and lungs.

\section{Ophthalmic Pathology}

Gross analysis revealed scattered retinal hemorrhages in the posterior pole of the left eye, with no additional abnormalities. Histologic examination demonstrated occasional retinal hemorrhages, as well as a mild, bilateral, uveal lymphohistiocytic infiltrate affecting the choroid, ciliary body, trabecular meshwork, and focally the iris. Hemophagocytosis was absent (Fig. 2), and special stains
2

Ocul Oncol Pathol 2018;4:1-11 DOI: $10.1159 / 000475551$
Vizcaino/Eberhart/Rodriguez 


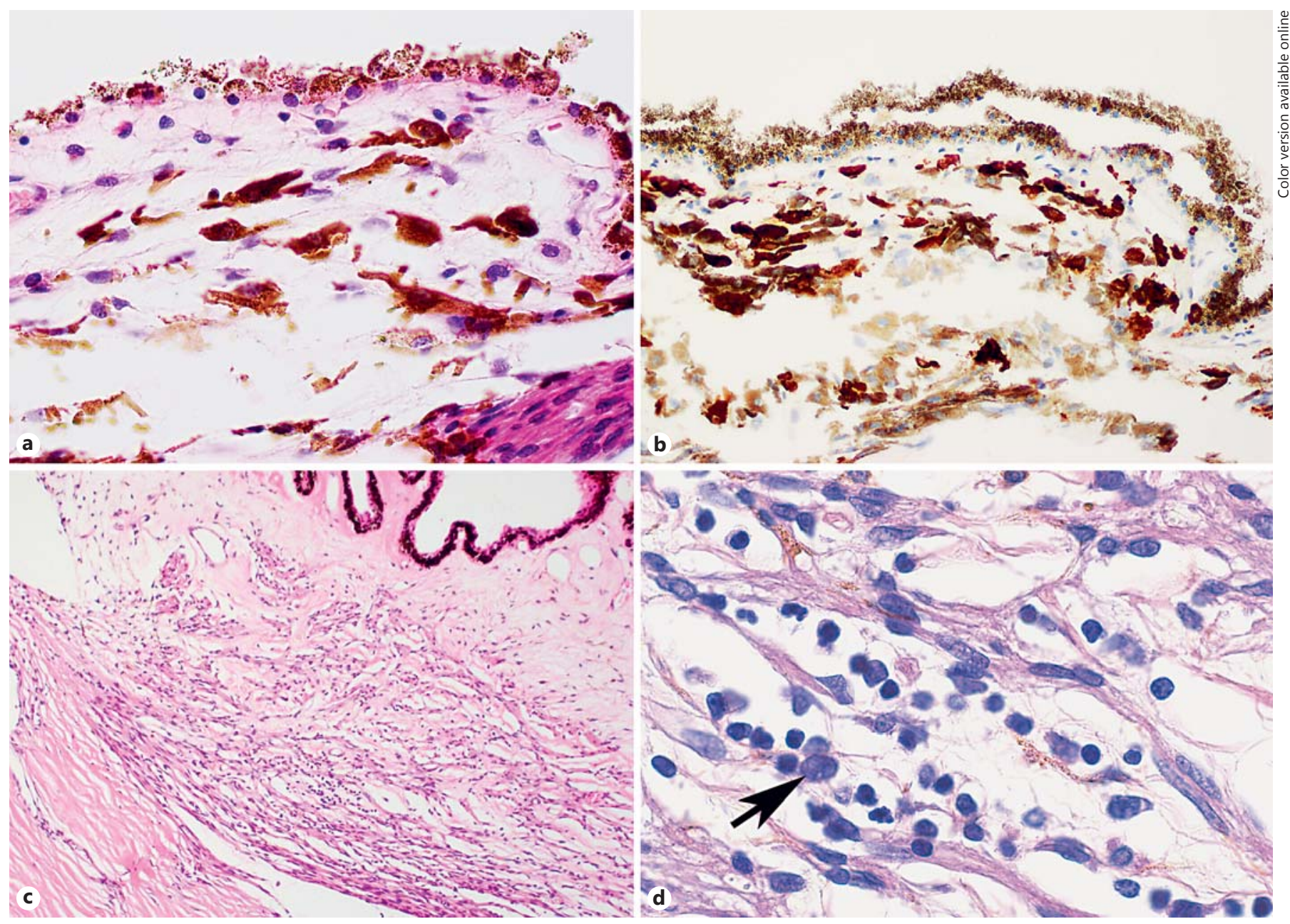

Fig. 1. Pathologic features of hemophagocytic lymphohistiocytosis with intraocular involvement (Case 1). Intraocular involvement was very subtle at the H\&E level in case 1 (a) but evident with CD163 immunohistochemistry (b). Focal involvement by chronic inflammation and macrophages of the ciliary body in particular was observed in $\mathrm{H} \& \mathrm{E}$ (c, d; arrow).

were negative for microorganisms (PAS, GMS, AFB) or significant iron (Prussian blue) deposition. Besides the uveal histiocytic infiltrate, CD163 antibody also demonstrated rare macrophages extending to the retina and optic nerve. CD3 immunostaining highlighted scattered $\mathrm{T}$ lymphocytes, while CD20 expression was present in only few B lymphocytes. No BRAFp.V600E mutant protein was detected by immunohistochemistry.

\section{Case 3}

Clinical History

The patient was a 49 -year-old male with a history of fevers, night sweats, dyspnea, fatigue, and a $~ 40$-pound unintentional weight loss. A general medical evaluation revealed splenomegaly, as well as elevated serum ferritin $(327,843 \mathrm{mg} / \mathrm{dL})$, transaminases, and soluble IL-2 receptor $(8,995 \mathrm{U} / \mathrm{mL})$. Bone marrow biopsies showed increased cellularity with focal hemophagocytosis. A genetic workup for HLH was negative. Treatment with prednisone and cyclosporine was started, followed by splenectomy and plasmapheresis, without improvement. After a short stabilization period with dexamethasone and etoposide, he presented with DIC, multiple infections, systemic bleeding, and nonspecific visual and auditory disturbances and died 18 months after diagnosis.
Ocular Hemophagocytic Lymphohistiocytosis
Ocul Oncol Pathol 2018;4:1-11 DOI: $10.1159 / 000475551$ 


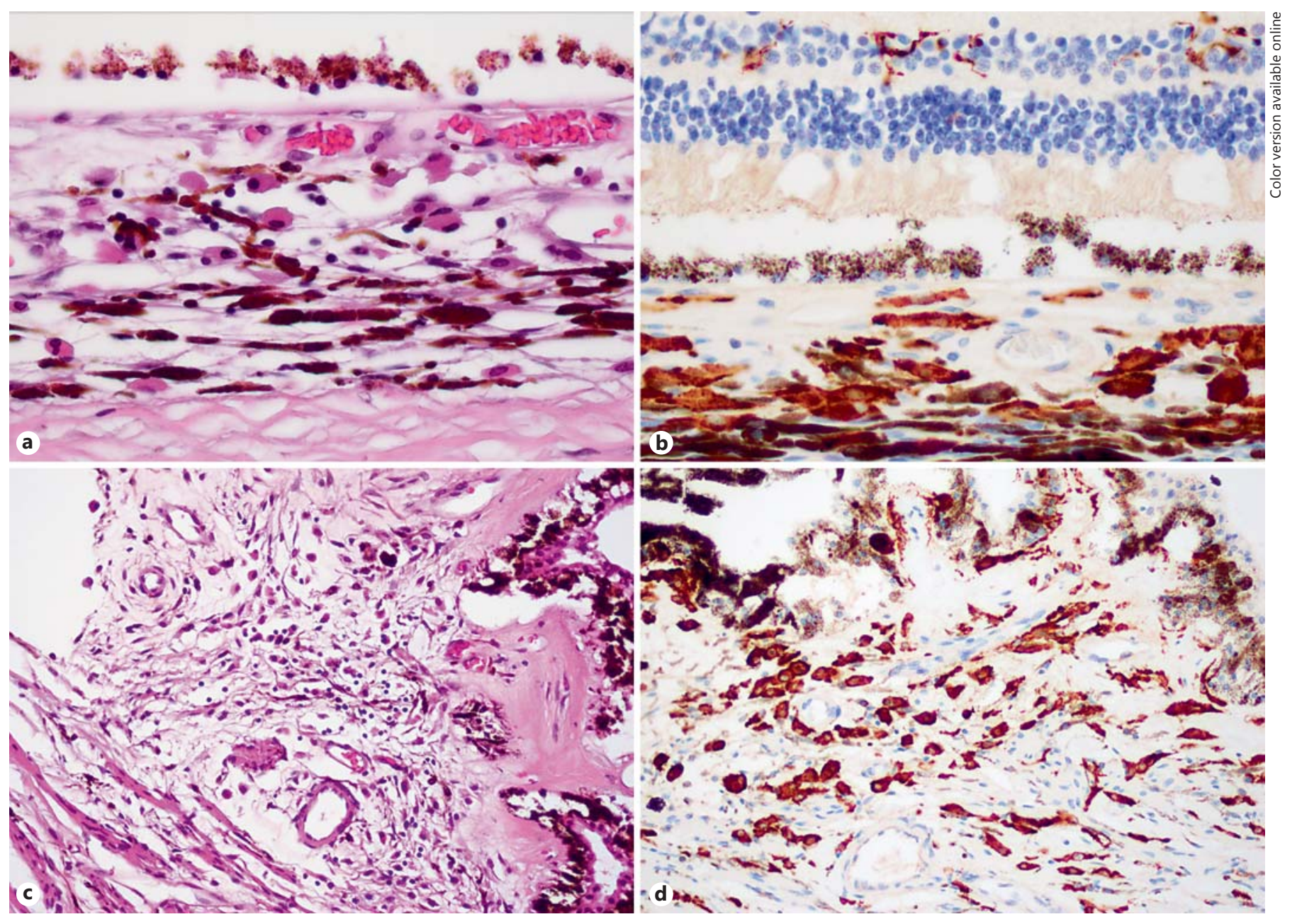

Fig. 2. Pathologic features of hemophagocytic lymphohistiocytosis with intraocular involvement (Case 2). A moderate histiocytic infiltrate involved the choroid (H\&E; a), retina (CD163; b), and trabecular meshwork (H\&E in $\mathbf{c}$ and CD163 in d).

\section{Autopsy Findings}

The general autopsy revealed a hypocellular bone marrow with degenerative changes and lymph nodes with lymphocyte depletion, consistent with treatment effect. Jaundice and hepatomegaly with cholestasis were present. Widespread hemorrhages were also identified, including the pons, subarachnoid space, lungs, bowel, left adrenal gland, and skin.

\section{Ophthalmic Pathology}

There were no gross abnormalities. Histologic sections showed a diffuse, bilateral inflammatory infiltrate consisting of macrophages with rare lymphocytes involving the choroid and extending focally to the ciliary body and iris, some of them with round, eosinophilic, intracellular material suggestive of hemophagocytosis (Fig. 3) as well as significant iron deposition (Prussian blue). Immunohistochemical stain for CD163 was strongly and diffusely positive in uveal macrophages, as well as in scattered histiocytes present in the retina. BRAFp.V600E mutation was not detected using immunohistochemistry. PAS stain was negative for microorganisms.

\section{Histologic and Immunohistochemical Examination of Control Eyes}

As a control group, 4 eyes obtained at autopsy from patients with similar ages to our study cohort were examined (see online suppl. Table 1; www. karger.com/doi/10.1159/000475551). Rare macrophages were encountered within vessels only by $\mathrm{H} \& \mathrm{E}$ in contrast
4

Ocul Oncol Pathol 2018;4:1-11 DOI: 10.1159/000475551
Vizcaino/Eberhart/Rodriguez 

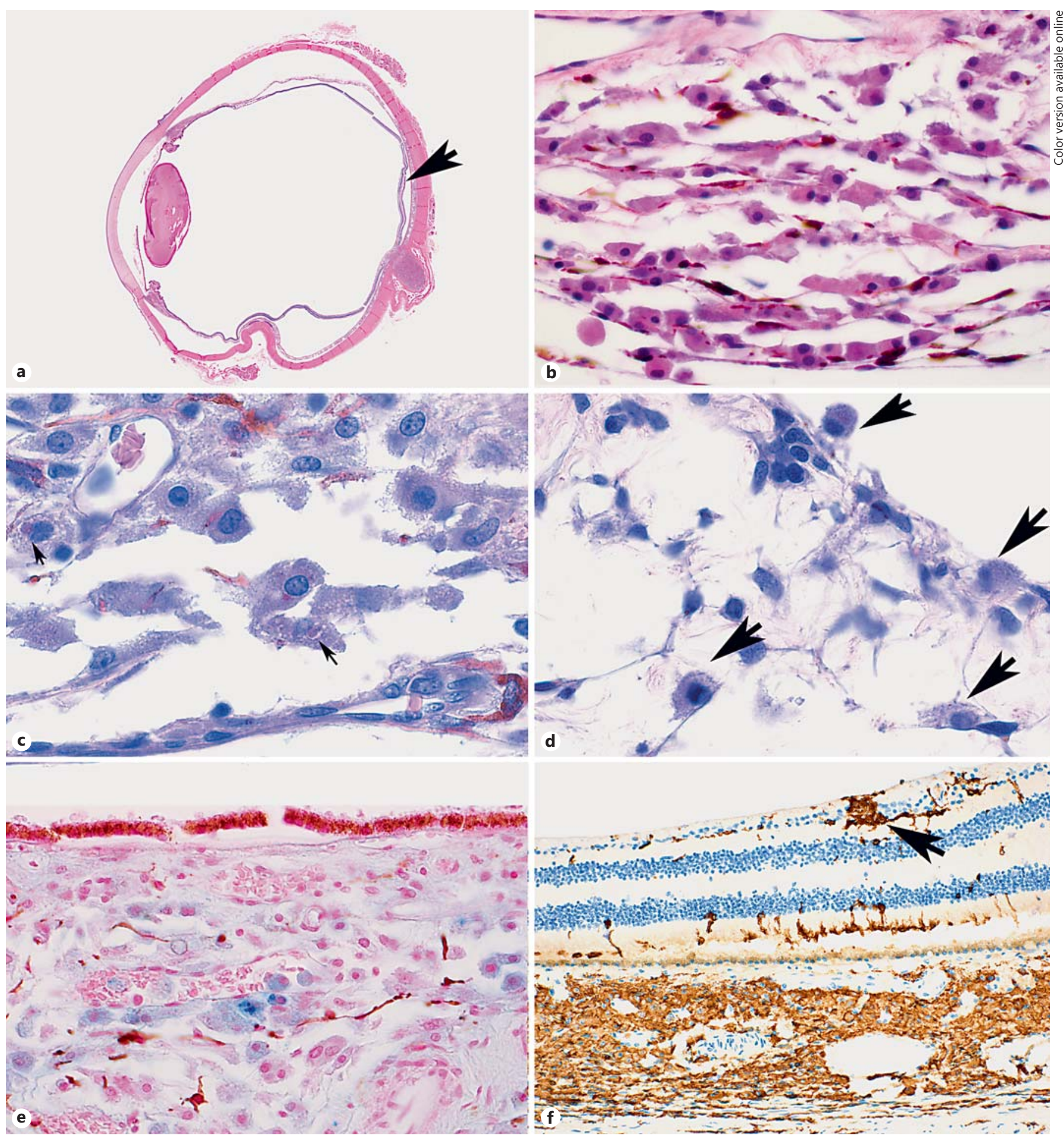

Fig. 3. Pathologic features of hemophagocytic lymphohistiocytosis with intraocular involvement (Case 3). Marked histiocytic infiltrate involving the choroid (arrow in a; b). Focal hemophagocytosis was identified (arrows, c), as well as involvement of the iris (arrows, d). Iron deposition was conspicuous (e Prussian blue), and focal retinal involvement was identified through immunohistochemistry (f CD163, arrow).

Ocular Hemophagocytic Lymphohistiocytosis
Ocul Oncol Pathol 2018;4:1-11

DOI: 10.1159/000475551 

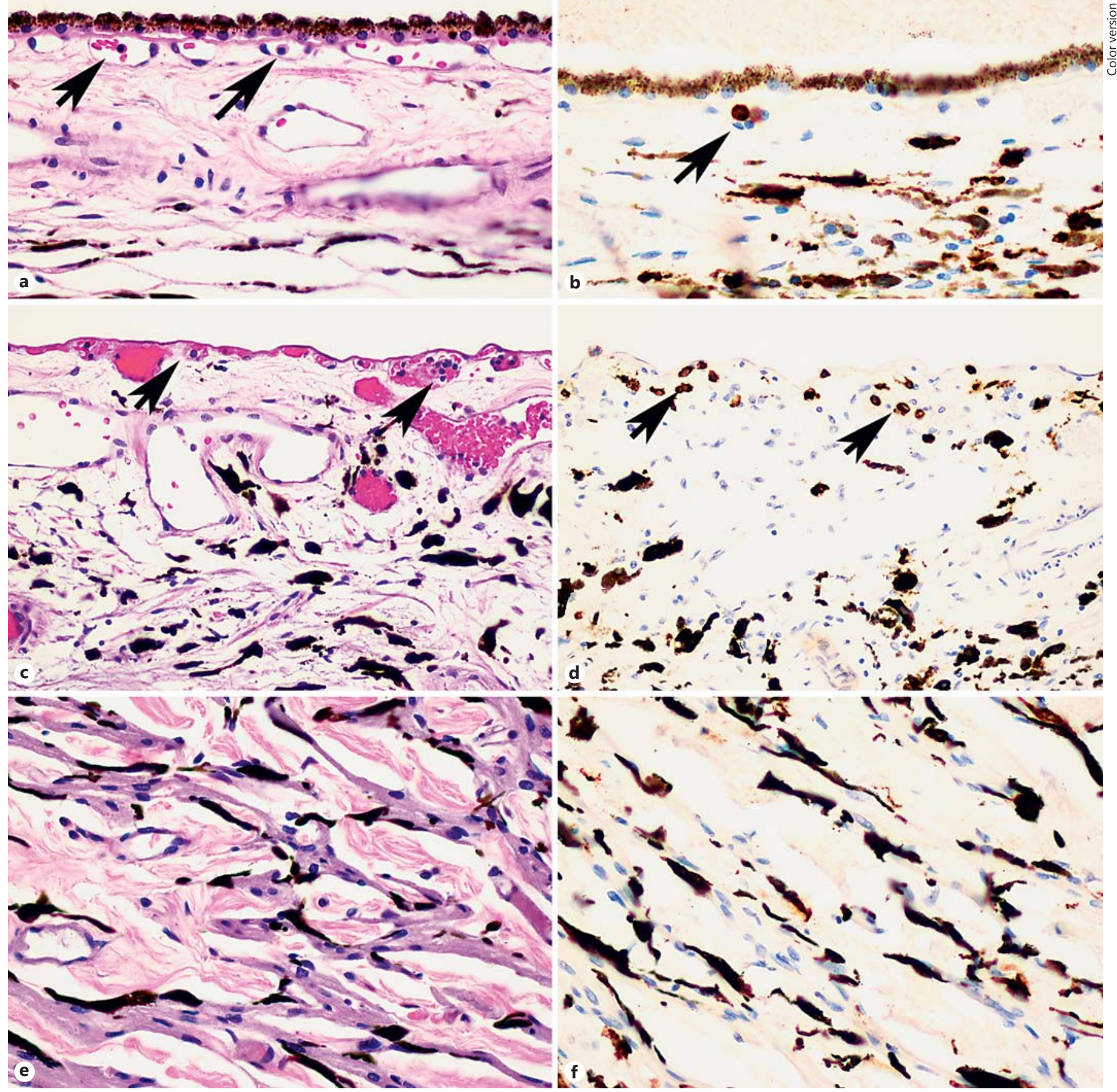

Fig. 4. Histologic and immunohistochemical analysis of control autopsy eyes. H\&E (a, c) and CD163 immunohistochemistry $(\mathbf{b}, \mathbf{d})$ highlight only few macrophages in the choroid and only in association with microvessels (arrows). Macrophages were even less conspicuous in the ciliary body (e, f) in contrast to the study cases (Fig. 1-3). 
to our study cases (Fig. 4). Although CD163 immunoreactivity was difficult to interpret given choroidal pigment, immunoreactivity in cells with a rounded morphology consistent with macrophages was largely limited to vessels in the choroid and uniformly absent in the ciliary body (Fig. 4). Rare CD163+ cells with a dendritic morphology were identified in the retina, but to a lesser extent than our study cases.

\section{Discussion}

HLH was initially thought to be a sporadic neoplastic proliferation of histiocytes and designated in 1939 as "histiocytic medullary reticulosis" by Scott and Robb-Smith. In 1952, Farquhar described it as a familial immune dysregulatory disorder presenting in childhood. The term familial hemophagocytic reticulosis was then changed to primary or familial HL and subsequently, nongenetic causes were recognized (i.e., secondary HLH) $[1,4]$. While primary HLH consists of different monogenic alterations that derive from impaired cytotoxicity of natural killer cells (NK) and CD8+ cytotoxic T lymphocytes (CTL), secondary HLH presents as an acquired complication in several contexts such as infections, malignant neoplasms, autoimmune diseases, post-transplantation, or is iatrogenically induced (Table 1) [8-15]. Regardless of the etiology, HLH is characterized by an uncontrolled activation of NK/CTL that provokes the release of large amounts of proinflammatory cytokines such as IFN- $\gamma$, TNF- $\alpha$, GM-CSF, M-CSF, and IL-2, resulting in hyperstimulation and systemic infiltration by macrophages which, in turn, phagocytose blood cells, mostly red blood cell precursors, and secrete other cytokines responsible for myelosuppression, endothelial damage with coagulopathy, tissue injury, and NK/CTL incessant activation (IL-1, IL6, and TNF- $\alpha$ ) (Fig. 5) [2-4]. Histologically, HLH shows a nonspecific multiorgan infiltration by macrophages associated with variable amounts of lymphocytes, especially affecting the bone marrow, lymph nodes, spleen, liver,

\section{(Footnote for Table 1)}

Modified from the revised classification of histiocytoses and neoplasms of the macrophage-dendritic cell lineages (Histiocyte Society, 2016). HLH, hemophagocytic lymphohistiocytosis; FLH, familial lymphohistiocytosis; XLP, X-linked lymphoproliferative syndrome; EBV, Epstein-Barr virus; CMV, citomegalovirus; HIV, human immunodeficiency virus; NK, natural killer; MAS, macrophage activation syndrome; SoJIA, systemic-onset juvenile idiopathic arthritis; SLE, systemic lupus erythematous.

Ocular Hemophagocytic

Lymphohistiocytosis
Table 1. Classification of hemophagocytic lymphohistiocytosis

Primary HLH: mendelian inherited conditions leading to HLH

Lymphocyte cytotoxic defects

FHL2 (PRF1)

FHL3 (UNC13D)

FHL4 (STX11)

FHL5 (STXBP2)

XLP1 $(S H 2 D 1 A)$

Griscelli syndrome type $2(R A B 27 A)$

Chediak-Higashi syndrome ( $L Y S T)$

Abnormalities of inflammasome activation

XLP2 (BIRC4)

NLRC4

Defined mendelian disorders affecting inflammation

Lysinuric protein intolerance (SLC7A7)

HMOX1

Others

Familial (apparently mendelian) HLH of unknown origin

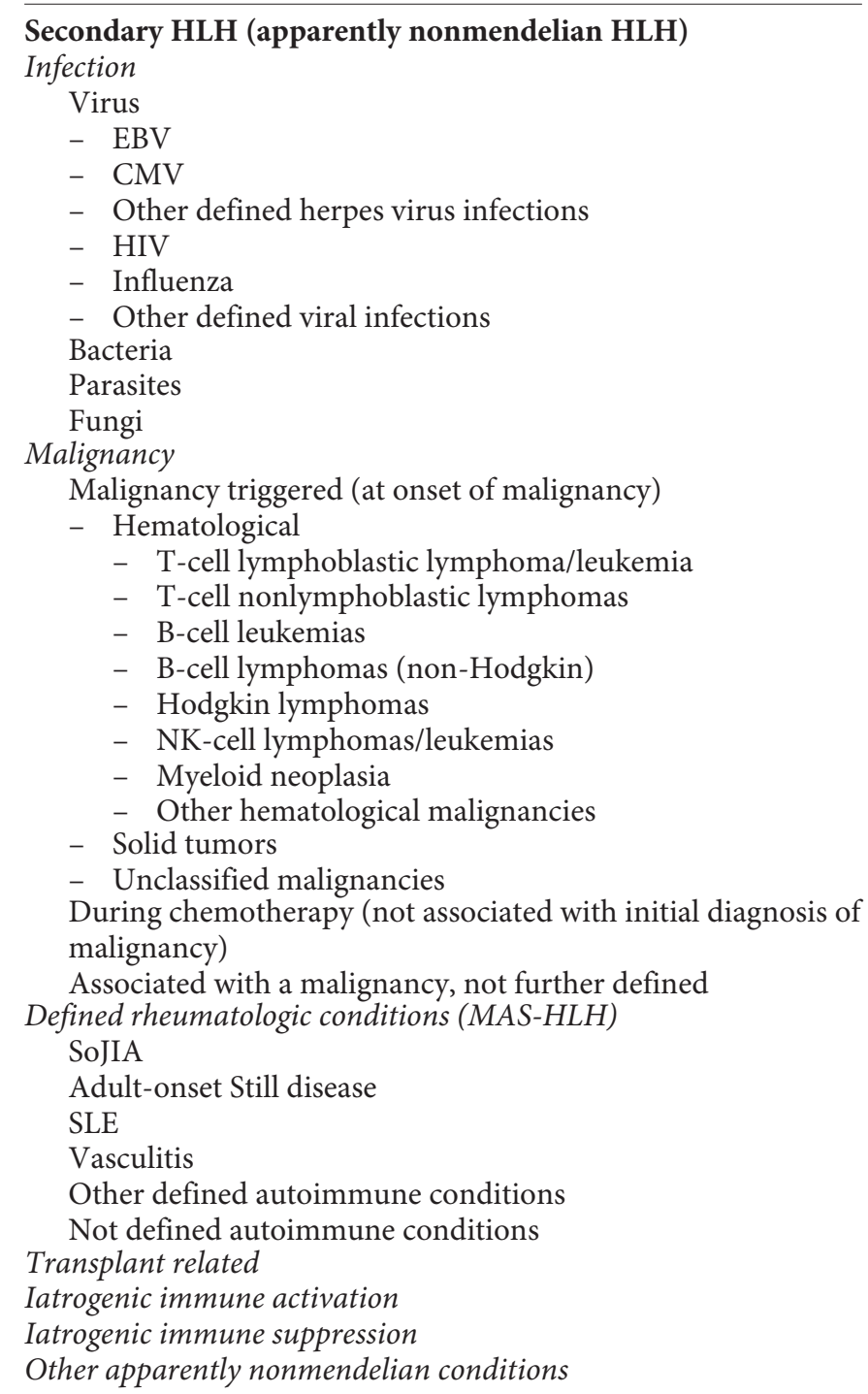

HLH of unknown/uncertain origin

Ocul Oncol Pathol 2018;4:1-11

DOI: $10.1159 / 000475551$ 
Fig. 5. Pathophysiology of hemophagocytic lymphohistiocytosis. HLH, hemophagocytic lymphohistiocytosis; NK, natural killer; CTL, cytotoxic T lymphocytes; RBC, red blood cells.

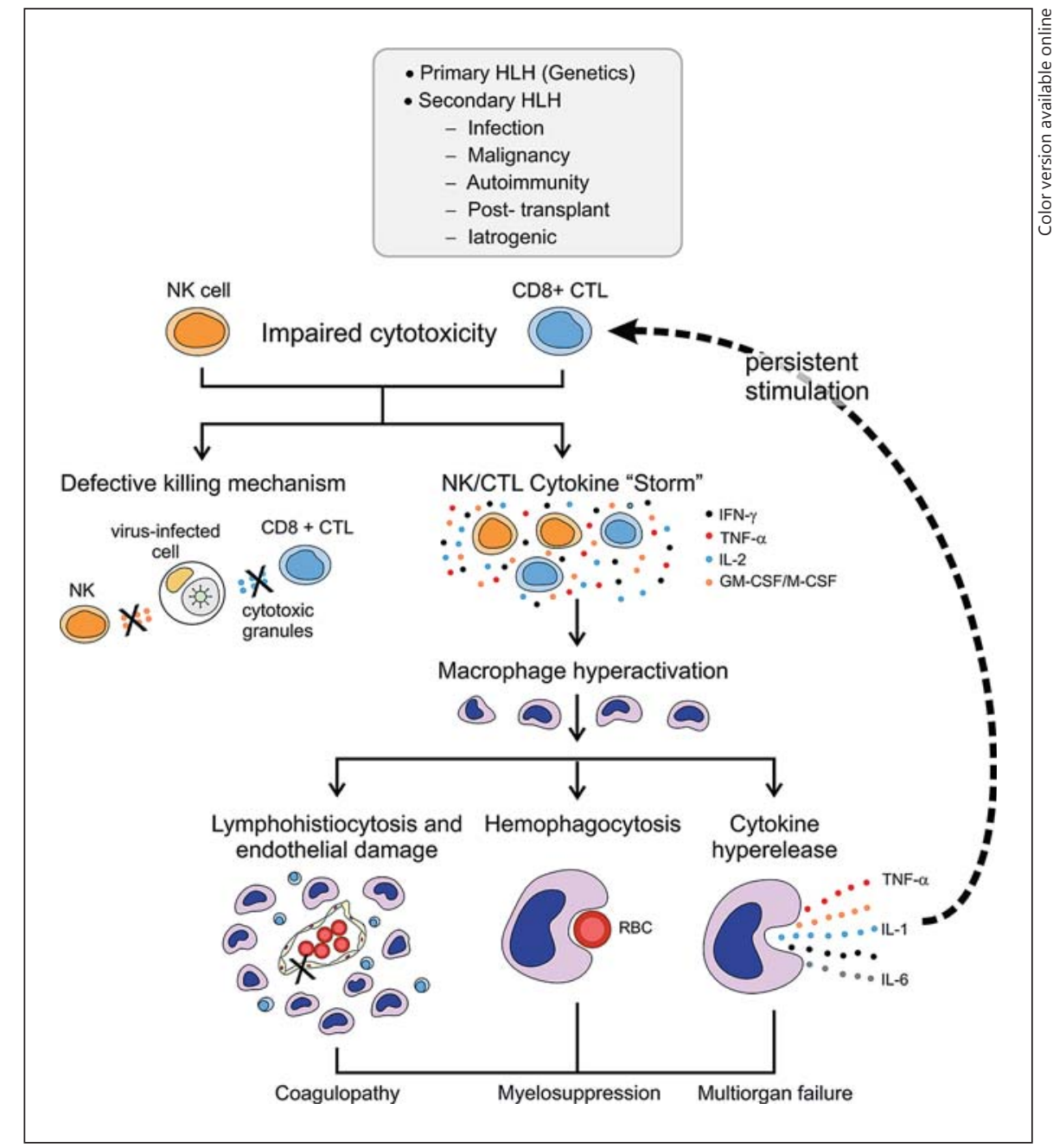

Table 2. Diagnostic criteria for hemophagocytic lymphohistiocytosis (HLH; Histiocyte Society 2004 pediatric study)

1 A molecular diagnosis consistent with HLH

or

2 Five of the 8 following criteria:

- Persistent fever

- Splenomegaly

- Cytopenias (affecting at least 2 of 3 lineages in the peripheral blood):

- Hemoglobin $<9 \mathrm{~g} / 100 \mathrm{~mL}$ (in infants $<4$ weeks: hemoglobin $<10 \mathrm{~g} / 100 \mathrm{~mL}$ )

- Platelets $<100 \times 10^{3} / \mathrm{mL}$

- Neutrophils $<1 \times 10^{3} / \mathrm{mL}$

- Hypertriglyceridemia (fasting, $\geq 265 \mathrm{mg} / 100 \mathrm{~mL}$ ) and/or hypofibrinogenemia ( $\leq 150 \mathrm{mg} / 100 \mathrm{~mL}$ )

- Hemophagocytosis in the bone marrow, spleen or lymph nodes, without evidence of malignancy

- Low or absent natural killer cell activity

- Ferritin $\geq 500 \mathrm{ng} / \mathrm{mL}$

- Soluble IL-2 receptor $(\mathrm{CD} 25)>2,400 \mathrm{U} / \mathrm{mL}$ central nervous system, and skin, which explains the consistent clinical manifestations in these patients (fever, cytopenias, lymphadenopathy, hepatosplenomegaly with liver dysfunction, skin rash, and diverse neurologic alterations) $[1,2,4,8]$. Hemophagocytosis is a distinctive feature, and its presence in the bone marrow, spleen, or lymph nodes is one of the current diagnostic criteria (Table 2). However, the absence of this morphologic finding is not uncommon at extralymphoid sites and does not rule out the diagnosis $[8,16]$.

Of interest, intraocular involvement is an uncommon presentation of HLH [17-25], and, to our knowledge, histologic findings have been previously illustrated only in a handful of cases, all of them pediatric at presentation (ranging in the age from 9 weeks to 7 years, median 2.1 years) (Table 3) [26-29]. Except for the adult onset, the clinical and histologic findings in our present cases are somewhat similar to those previously reported. Cases 2
8
Ocul Oncol Pathol 2018;4:1-11 DOI: $10.1159 / 000475551$
Vizcaino/Eberhart/Rodriguez 
Table 3. Reported cases of hemophagocytic lymphohistiocytosis with ocular involvement

\begin{tabular}{|c|c|c|c|c|c|}
\hline First author [ref.], year & Age & Gender & Ocular affected sites & $\begin{array}{l}\text { Ocular } \\
\text { hemophagocytosis }\end{array}$ & Survival $^{\mathrm{a}}$ \\
\hline Petersen [26], 1968 & 16 months & Male & $\begin{array}{l}\text { Optic nerve } \\
\text { Retina } \\
\text { Vitreous } \\
\text { Choroid } \\
\text { Ciliary body } \\
\text { Iris } \\
\text { Anterior chamber } \\
\text { Trabecular meshwork }\end{array}$ & Present & 1 week \\
\hline Appen [27], 1976 & 5 months & Female & $\begin{array}{l}\text { Optic nerve } \\
\text { Retina } \\
\text { Vitreous } \\
\text { Iris } \\
\text { Iridocorneal angle }\end{array}$ & Present & 17 days \\
\hline Lubin [28], 1981 & 7 years & Male & Choroid & Absent & 2 months \\
\hline \multirow[t]{2}{*}{ Park [29], 1997} & 19 months & Female & $\begin{array}{l}\text { Optic nerve } \\
\text { Choroid }\end{array}$ & Present & 13 months \\
\hline & 9 weeks & Female & $\begin{array}{l}\text { Choroid } \\
\text { Ciliary body } \\
\text { Iris } \\
\text { Trabecular meshwork }\end{array}$ & Present & 9 days \\
\hline Present Case 1 & 70 years & Male & $\begin{array}{l}\text { Optic nerve } \\
\text { Retina } \\
\text { Choroid } \\
\text { Ciliary body } \\
\text { Iris } \\
\text { Trabecular meshwork }\end{array}$ & Absent & 2 months \\
\hline Present Case 2 & 20 years & Male & $\begin{array}{l}\text { Optic nerve } \\
\text { Retina } \\
\text { Choroid } \\
\text { Ciliary body } \\
\text { Iris } \\
\text { Trabecular meshwork }\end{array}$ & Absent & 3 months \\
\hline Present Case 3 & 49 years & Male & $\begin{array}{l}\text { Retina } \\
\text { Choroid } \\
\text { Ciliary body } \\
\text { Iris }\end{array}$ & Present (focal) & 18 months \\
\hline
\end{tabular}

${ }^{\text {a }}$ From the onset of symptoms.

and 3 satisfied at least 5 of the 8 contemporary criteria, while case 1 satisfied 4 of the criteria, although several of the laboratory tests currently incorporated into the diagnostic criteria were not routinely tested at the time. However, most findings were consistent with the syndrome, including pathologic evidence of hemophagocytosis in the hematolymphoid organs. With slight variations in the affected sites, all pediatric and adult cases showed a bilateral, lymphohistiocytic infiltrate in the uveal tract, particularly in the choroid, except for the case reported by Appen et al. [27], which had no choroidal involvement. In contrast, the choroid was the only intraocular affected site in the case reported by Lubin et al. [28]. This makes sense, since the choroid is a richly vascularized tissue that 
is frequently involved in systemic inflammatory and neoplastic disorders. Other documented sites are the optic nerve, retina, vitreous, anterior chamber, and trabecular meshwork [26, 27, 29]. From our perspective, another interesting finding is that the ocular involvement in each of the cases we present displayed not only a bilateral distribution but was also symmetric in terms of severity in each eye.

While 2 of our cases had a confirmed history of viral infection, the third case lacked an evident trigger and, interestingly, survival in the latter was also the longest among all the cases (18 months vs. 3 months on average). Additionally, all of our cases lacked immunoreactivity for BRAF p.V600E, which helped in excluding diffuse histiocytoses that may affect the ocular/periocular structures; e.g., Erdheim-Chester disease, which have a high frequency of $B R A F$ mutations [30].

Many of these disorders tend to involve the orbital soft tissues, which differs from the uniform predominant choroidal involvement by HLH in our series. Other inflammatory disorders, such as sarcoidosis, also have a predilection for the uveal tract. However, these are easily distinguished from HLH on clinical and morphologic grounds. In summary, HLH is a rare, systemic, and frequently lethal immunologic disorder mostly presenting in the pediatric population and with only few cases with pathologically documented histologic abnormalities. This unique series also emphasizes the importance of keeping this entity in mind for the differential diagnosis of adult patients with suggestive signs and symptoms presenting with visual impairment in the clinic. Although with variable severity, histologic findings in HLH with ocular involvement seem to be similar regardless of age, gender, and etiology. The consistent choroidal anatomical distribution may be explained by the unique microvasculature in this region. Of interest, prior studies in normal and abnormal eyes at autopsy have documented components of the immune system, including macrophages and CD163 + cells in the retina and uveal tract [31, 32]. Many of these have a consistent dendritic morphology. In our study using age-matched control eyes, CD163+ cells with macrophage morphology were largely limited to choroidal vessels, in contrast to the 3 eyes of the patients with HLH, where infiltrates, although of variable severity, were more diffuse and present outside vessels.

While the reason for the extension to other sites (ciliary body, iris, retina, and optic nerve) is unclear, it may be secondary to chronicity or increased severity in a subset of cases. Future studies including more contemporary cases should increase our understanding of this clinicopathologic entity and in particular its distinctive intraocular manifestations.

\section{Statement of Ethics}

The study was performed under Institutional Review Board approval, and all ethical standards were followed.

\section{Disclosure Statement}

The authors of this article have no conflicts of interest to disclose.

\section{Author Contributions}

M.A.V. wrote the manuscript, and M.A.V., C.G.E., and F.J.R. conceived the project, gathered the data, reviewed the cases, planned the experiments, and approved the manuscript in its final form.

\section{References}

1 Madkaikar M, Shabrish S, Desai M: Current updates on classification, diagnosis and treatment of hemophagocytic lymphohistiocytosis (HLH). Indian J Pediatr 2016;83:434-443.

2 Yang SL, Xu XJ, Tang YM, et al: Associations between inflammatory cytokines and organ damage in pediatric patients with hemophagocytic lymphohistiocytosis. Cytokine 2016;85:14-17.

3 Kuriyama T, Takenaka K, Kohno K, et al: Engulfment of hematopoietic stem cells caused by down-regulation of CD47 is critical in the pathogenesis of hemophagocytic lymphohistiocytosis. Blood 2012;120:4058-4067.
4 Morimoto A, Nakazawa Y, Ishii E: Hemophagocytic lymphohistiocytosis: pathogenesis, diagnosis, and management. Pediatr Int 2016;58:817-825.

5 Suzuki N, Morimoto A, Ohga S, Kudo K, Ishida Y, Ishii E; HLH/LCH Committee of the Japanese Society of Pediatric Hematology: Characteristics of hemophagocytic lymphohistiocytosis in neonates: a nationwide survey in Japan. J Pediatr 2009;155:235-238.
6 Hayden A, Park S, Giustini D, Lee AY, Chen LY: Hemophagocytic syndromes (HPSs) including hemophagocytic lymphohistiocytosis (HLH) in adults: a systematic scoping review. Blood Rev 2016;30:411-420.

7 Zhang Z, Wang J, Ji B, et al: Clinical presentation of hemophagocytic lymphohistiocytosis in adults is less typical than in children. Clinics (Sao Paulo) 2016;71:205-209.

8 Emile JF, Abla O, Fraitag S, et al: Histiocyte Society. Revised classification of histiocytoses and neoplasms of the macrophage-dendritic cell lineages. Blood 2016;127:2672-2681. 
9 Cağdaş D, Ozgür TT, Asal GT, et al: Griscelli syndrome types 1 and 3: analysis of four new cases and long-term evaluation of previously diagnosed patients. Eur J Pediatr 2012;171: 1527-1531.

10 Shaw TY, Schivo M: Weathering a cytokine storm: a case of EBV-induced hemophagocytic lymphohistiocytosis. J Investig Med High Impact Case Rep 2016; 4: 2324709616647409.

11 Rathnayake PV, Kularathne WK, De Silva GC, et al: Disseminated tuberculosis presenting as hemophagocytic lymphohistiocytosis in an immunocompetent adult patient: a case report. J Med Case Rep 2015;9:294.

12 Ferguson-Paul K, Mangum S, Porter A, Leventaki V, Campbell P, Wolf J: Hemophagocytic lymphohistiocytosis and progressive disseminated histoplasmosis. Emerg Infect Dis 2016;22:1119-1121.

13 Matnani R, Ganapathi KA: Hemophagocytic lymphohistiocytosis associated with visceral leishmaniasis. Blood 2016;127:513.

14 Tamamyan GN, Kantarjian HM, Ning J, et al: Malignancy-associated hemophagocytic lymphohistiocytosis in adults: relation to hemophagocytosis, characteristics, and outcomes. Cancer 2016;122:2857-2866.

15 Sinno MG, Rosen D, Wittler R: Concomitant presentation of hemophagocytic lymphohistiocytosis and posttransplant lymphoproliferative disease-like lymphoma in a mildly immunosuppressed leukemia patient: an unusual association. Pediatr Blood Cancer 2016;63: 1474-1476.
16 Goel S, Polski JM, Imran H: Sensitivity and specificity of bone marrow hemophagocytosis in hemophagocytic lymphohistiocytosis. Ann Clin Lab Sci 2012;42:21-25.

17 Matsubara K, Nigami $H$, Harigaya $H$, et al: Ocular involvement and visual sequelae in hemophagocytic lymphohistiocytosis in association with congenital dyfsfibrinogenemia. Pediatr Hematol Oncol 1998;15:365-370.

18 Kawamura H, Hatsukawa Y, Furukawa A, Inoue M, Kawa K: Ophthalmic findings in a case of hemophagocytic syndrome. Am J Ophthalmol 1997; 124:261-263.

19 Liao PM, Thompson JT: Ophthalmic manifestations of virus-associated hemophagocytic syndrome. Arch Ophthalmol 1991;109:777.

20 Suhr KS, Chiang MF, Flynn JT, Engelbert M: Ocular involvement in hemophagocytic syndrome: a novel funduscopic manifestation and review of the literature. Retin Cases Brief Rep 2016;1D:345-348.

21 Lee EW, Mieler WF: Ocular findings in a patient with hemophagocytic syndrome. Arch Ophthalmol 2006;124:1656-1658.

22 Yao H, Liu Y, Ding W, Xu Y, Cheng Y: Ocular findings in a patient with virus-associated hemophagocytic syndrome. Ocul Immunol Inflamm 2012;20:233-234.

23 Cai CX, Siringo FS, Odel JG, et al: Downbeat nystagmus secondary to familial hemophagocytic lymphohistiocytosis. J Neuroophthalmol 2014;34:57-60.

24 Li X, Ma Y, Tang J, Chen T, Ma X: A hemophagocytic lymphohistiocytosis patient that presented with unilateral panuveitis. Ocul Immunol Inflamm 2017;25:275-277.
25 Chong KW, Lee JH, Choong CT, et al: Hemophagocytic lymphohistiocytosis with isolated central nervous system reactivation and optic nerve involvement. J Child Neurol 2012;27: 1336-1339.

26 Petersen RA, Kuwabara T: Ocular manifestations of familial lymphohistiocytosis. Arch Ophthalmol 1968;79:413-416.

27 Appen RE, Weber SW, de Venecia G, Rhein GM: Ocular and cerebral involvement in familial lymphohistiocytosis. Am J Ophthalmol 1976;82:758-766.

28 Lubin JR, Walton DS, Albert DM: Two cases of suspected familial erythrophagocytic lymphohistiocytosis. Am J Ophthalmol 1981;91: 743-749.

29 Park JK, Palexas GN, Streeten BW, Green WR: Ocular involvement in familial erythrophagocytic lymphohistiocytosis. Graefes Arch Clin Exp Ophthalmol 1997;235:647652.

30 Haroche J, Charlotte F, Arnaud L, et al: High prevalence of BRAF V600E mutations in Erdheim-Chester disease but not in other nonLangerhans cell histiocytoses. Blood 2012; 120:2700-2703.

31 Lad EM, Cousins SW, Van Arnam IS, Proia AD: Abundance of infiltrating CD163+ cells in the retina of postmortem eyes with dry and neovascular age-related macular degeneration. Graefes Arch Clin Exp Ophthalmol 2015;253:1941-1945.

32 McMenamin PG: The distribution of immune cells in the uveal tract of the normal eye. Eye (Lond) 1997;11(Pt 2):183-193. 